\title{
Prion infectivity is encoded exclusively within the structure of proteinase K- resistant fragments of synthetically generated recombinant $\mathrm{PrP}^{\mathrm{Sc}}$
}

\author{
Fei Wang ${ }^{1}$, Xinhe Wang ${ }^{1}$, Romany Abskharon ${ }^{1,2}$ and Jiyan $\mathrm{Ma}^{1 *}$ (1)
}

\begin{abstract}
Transmissible spongiform encephalopathies, also known as prion diseases, are a group of fatal neurodegenerative disorders affecting both humans and animals. The central pathogenic event in prion disease is the misfolding of normal prion protein $\left(\operatorname{PrP}^{C}\right)$ into the pathogenic conformer, $\operatorname{PrP}^{S C}$, which self-replicates by converting $\operatorname{Pr} P^{C}$ to more of itself. The biochemical hallmark of $\mathrm{PrP}^{\mathrm{SC}}$ is its $\mathrm{C}$-terminal resistance to proteinase $\mathrm{K}$ (PK) digestion, which has been historically used to define $\mathrm{PrP}^{\mathrm{Sc}}$ and is still the most widely used characteristic for prion detection. We used PKresistance as a biochemical measure for the generation of recombinant prion from bacterially expressed recombinant PrP. However, the existence of both PK- resistant and -sensitive PrPSc forms in animal and human prion disease led to the question of whether the in vitro-generated recombinant prion infectivity is due to the PKresistant or -sensitive recombinant PrP forms. In this study, we compared undigested and PK-digested recombinant prions for their infectivity using both the classical rodent bioassay and the cell-based prion infectivity assay. Similar levels of infectivity were detected in PK-digested and -undigested samples by both assays. A time course study of recombinant prion propagation showed that the increased capability to seed the conversion of endogenous PrP in cultured cells coincided with an increase of the PK-resistant form of recombinant PrP. Moreover, prion infectivity diminished when recombinant prion was subjected to an extremely harsh PK digestion. These results demonstrated that the infectivity of recombinant prion is encoded within the structure of the PK-resistant PrP fragments. This characteristic of recombinant prion, that a simple PK digestion is able to eliminate all PK-sensitive (non-infectious) PrP species, makes possible a more homogenous material that will be ideal for dissecting the molecular basis of prion infectivity.
\end{abstract}

Keywords: Prion disease, Prion, PrPSc, Recombinant prion, Proteinase K-resistant, Prion infectivity, Protein conformation

\section{Introduction}

Prion diseases are a group of fatal neurodegenerative disorders affecting both human and animals [20]. Prion is the causative agent of prion disease, which is a protein-conformation-based pathogen called $\operatorname{PrP}^{\mathrm{Sc}}$ $[19,20]$. The normal form of prion protein, $\operatorname{PrP}^{C}$, is a glycosylphosphatidylinositol-anchored protein widely expressed in tissues and enriched in the central nervous system $[2,20] \cdot \operatorname{PrP}^{\mathrm{Sc}}$ propagates by coercing the

\footnotetext{
* Correspondence: Jiyan.Ma@vai.org

${ }^{1}$ Center for Neurodegenerative Science, Van Andel Research Institute, 333

Bostwick Avenue N.E., Grand Rapids, Ml 49503, USA

Full list of author information is available at the end of the article
}

conversion of $\mathrm{PrP}^{\mathrm{C}}$ into $\mathrm{PrP}^{\mathrm{Sc}}$, resulting in more $\mathrm{PrP}^{\mathrm{Sc}}$, neurodegeneration, and the manifestation of prion disease [12]. Structural studies have shown that $\operatorname{PrP}^{\mathrm{C}}$ contains a flexible $\mathrm{N}$-terminal region and a fully folded $\mathrm{C}$-terminal globular domain with three $\alpha$ helices $[22,23]$. No high-resolution structure of $\operatorname{PrP}^{\mathrm{Sc}}$ is available [41], but biophysical studies have provided strong evidence that $\operatorname{PrP}^{\mathrm{Sc}}$ is composed almost exclusively of $\beta$-sheeted structures [30,33], indicating that the $\operatorname{PrP}^{\mathrm{C}}$-to- $\operatorname{PrP}^{\mathrm{Sc}}$ conversion involves a major structural rearrangement. Elucidating the threedimensional structure of $\mathrm{PrP}^{\mathrm{Sc}}$, the structural basis of the $\mathrm{PrP}^{\mathrm{Sc}}$ seeding process, and the structural

(c) The Author(s). 2018 Open Access This article is distributed under the terms of the Creative Commons Attribution 4.0 International License (http://creativecommons.org/licenses/by/4.0/), which permits unrestricted use, distribution, and reproduction in any medium, provided you give appropriate credit to the original author(s) and the source, provide a link to the Creative Commons license, and indicate if changes were made. The Creative Commons Public Domain Dedication waiver (http://creativecommons.org/publicdomain/zero/1.0/) applies to the data made available in this article, unless otherwise stated. 
rearrangement of the $\operatorname{PrP}^{\mathrm{C}}$-to- $-\mathrm{PrP}^{\mathrm{Sc}}$ conversion are the major goals of current prion research. This information will provide the foundation for developing effective prophylactic and therapeutic strategies against these fatal neurodegenerative disorders [3].

Prions were once considered an unorthodox diseasecausing agent, but now it is clear that in other common, late-onset, neurodegenerative diseases, protein aggregates such as $A \beta$ and tau in Alzheimer's disease and $\alpha$ synuclein in Parkinson's disease are able to propagate their diseased conformations in a "prion-like" manner $[8,21,31]$. Among all these protein aggregates, $\operatorname{PrP}^{\mathrm{Sc}}$ is the only one that has been proven to be a diseasecausing agent. Elucidating the molecular mechanism of prion infectivity is not only important for combatting prion disease, but will also shed light on the molecular mechanisms of propagation of other protein aggregates.

Using bacterially expressed recombinant $\operatorname{PrP}($ rec PrP), we have generated recombinant prion $\left(\mathrm{recPrP}^{\mathrm{Sc}}\right)$ in vitro, which causes bona fide prion disease in wild-type animals $[36-38,40]$. Similar to brain-derived $\operatorname{PrP}^{\mathrm{Pc}}$, $\operatorname{rec} \operatorname{PrP}^{\mathrm{Sc}}$ exhibits the signature C-terminal PK resistance, is highly infectious, and has almost all the biological properties of a native prion in diseased tissue $[29,35,38]$. However, it is still unclear whether the prion infectivity is encoded within the structure of the $\mathrm{PK}$-resistant $\operatorname{recPrP}^{\mathrm{Sc}}$ fragments; that is, whether the $\mathrm{PK}$-resistant $\operatorname{rec} \mathrm{Pr} \mathrm{P}^{\mathrm{Sc}}$ fragments contain the full prion infectivity or some of the infectivity is actually from $\mathrm{PK}$-sensitive $\operatorname{recPrP}^{\mathrm{Sc}}$. The answer to this question is important, because it has been demonstrated in human and animal prion diseases that both PK-resistant and PK-sensitive $\mathrm{PrP}^{\mathrm{Sc}}$ forms exist and that both contribute to prion infectivity $[5,15,24-26,32]$. Therefore, some PK-sensitive recPrP ${ }^{\mathrm{Sc}}$ may be responsible for part or all of the recombinant prion infectivity.

The in vitro-generated recPrP $\mathrm{P}^{\mathrm{Sc}}$ provides an excellent platform for dissecting the molecular basis of prion infectivity. However, a difficulty of this type of study is the heterogeneity of the recPrP $\mathrm{P}^{\mathrm{Sc}}$ preparation. That is, multiple recPrP conformers are generated during the in vitro conversion process and less than $10 \%$ of recPrP becomes PK-resistant. Understanding whether the PK-resistant or PK-sensitive recPrP contributes to prion infectivity would have a huge impact on the mechanistic study of prion infectivity. If the infectivity were encoded by the PK-resistant recPrP ${ }^{\mathrm{Sc}}$ fragments, then $\mathrm{PK}$ digestion would remove all the PK-sensitive recPrP species and greatly enhance the homogeneity. If PK-sensitive recPrP is responsible for the infectivity, more effort will need to be spent on dissecting the PK-sensitive recombinant prion fraction.

We performed a detailed study of the replication process of $r e c \operatorname{PrP}^{\mathrm{Sc}}$ and found a clear association between the recPrP conformational change and the propagation of prion infectivity. We also compared the prion infectivity of PK-digested and -undigested recPrP $\mathrm{P}^{\mathrm{Sc}}$ samples using both a cell-based prion infectivity assay and a rodent bioassay. Our results clearly showed that recombinant prion infectivity was fully encoded within the PK-resistant conformation.

\section{Materials and methods Generation of recPrPsc}

The purification of recombinant murine $\operatorname{PrP} 23-230$, the preparation of substrates, and serial protein misfolding cyclic amplification (sPMCA) were performed as previously described [34, 36, 37]. For seeded sPMCA, $10 \mu \mathrm{L}$ of $\mathrm{recPrP}{ }^{\mathrm{Sc}}$ seed was added to the substrate and the mixture was subjected to one round of PMCA. After each round, $10 \mu \mathrm{L}$ of the product was transferred to a new tube containing $90 \mu \mathrm{l}$ of substrate for another round. To detect the generation of $\operatorname{recPrP}^{\mathrm{Sc}}, 10 \mu \mathrm{L}$ of PMCA product after each round (or at designated time points within the same 24-h round) was incubated with $10 \mu \mathrm{L}$ proteinase $\mathrm{K}$ (PK; $100 \mu \mathrm{g} / \mathrm{mL}$ unless stated otherwise) for $30 \mathrm{~min}$ at $37{ }^{\circ} \mathrm{C}$, followed by the addition of $2 \mathrm{mM}$ phenylmethylsulfonyl fluoride. The PK-digested samples were subjected to SDS-PAGE and western blotting. All the PK-resistant PrP fragments were detected using POM1 primary anti-PrP antibody [18].

The enzyme-linked immunospot (Elispot) cell infection assay The Elispot assay was adapted from previous studies [11, 13] with minor modifications. Briefly, $100 \mu \mathrm{L}$ of samples were collected after one round of PMCA (or at designated time points within the same round). The collected samples were either untreated or treated with benzonase, PK, or both, and centrifuged at $100,000 \times g$ and $4{ }^{\circ} \mathrm{C}$ for $1 \mathrm{~h}$. The pellets were then washed twice with PBS and centrifuged at 100,000 $\times g$ and $4{ }^{\circ} \mathrm{C}$ for $1 \mathrm{~h}$ after each wash. After the second wash, the pellets were resuspended in $100 \mu \mathrm{L}$ of CAD5 growth media (OPTI-MEM, 5\% BGS, and 1\% penicillin and streptomycin) and sonicated for $30 \mathrm{~s}$ using a cup-hold Misonic Sonicator (XL2020) at 50\% output. Then each sample was serially diluted, and $60 \mu \mathrm{L}$ of undiluted or diluted samples were used to infect CAD5 cells. After two 1:10 splits, 20,000 CAD5 cells/well were transferred to the Millipore 96-well Elispot plates (MSIPN4W) and subjected to the Elispot assay. The images were taken by a S6 Micro Analyzer (CTL Analyzers, LLC) and processed by the ImmunoSpot software (CTL Analyzers, LLC). The graph was generated using GraphPad Prism (GraphPad Software, Inc.). The end-point titration data was used to calculate the infectivity titer in CAD5 cells according to the Spearman-Karber formula.

\section{Mouse bioassays}

The mouse bioassays were performed as previously described [34, 36-38, 40]. In brief, $20 \mu \mathrm{L}$ of purified 
recPrP $\mathrm{P}^{\mathrm{Sc}}$, either untreated or treated with Benzonase, PK, or both, was inoculated into a mouse intracerebrally with or without serial dilution. The infectivity titer was calculated according to the Spearman-Karber formula.

\section{Ethics statement}

This study was carried out in accordance with the Guide for the Care and Use of Laboratory Animals of the National Institutes of Health. The protocols were approved by the Institutional Animal Care and Use Committee of the Van Andel Research Institute (Assurance Number A4383-01).

\section{Results}

Amplification of recPrP ${ }^{\mathrm{Sc}}$ in vitro was accompanied by an increase of prion infectivity

Previously, we demonstrated that $\mathrm{recPrP}^{\mathrm{Sc}}$ generated through sPMCA with recPrP and two cofactorsspecifically, 1-palmitoyl-2-oleoyl-sn-glycero-3-phospho-(1'rac-glycerol) (POPG) and total RNA isolated from normal mouse liver-is highly infectious to wild-type mice and has an infectious dose $50\left(\mathrm{ID}_{50}\right)$ around $10^{4} / \mu \mathrm{g}$ recPrP $[36,38]$. The mouse bioassay of prion infectivity is robust and accurate, but because of the time required and the cost, it is not well suited for detailed analysis of infectivity. The Elispot cell-based assay is a new prion infectivity assay $[13,14]$ that is quantitative and rapid. It has been used to reveal the relationship between prion infectivity and neurotoxicity [27] and the evolution of a prion when it is exposed to changing environments [11]. Because in vitro-generated $\operatorname{recPrP}^{\mathrm{Sc}}$ is able to chronically infect susceptible cultured cells [37], we adapted this assay for our study.

We compared the infectious titer of recPrP ${ }^{\mathrm{Sc}}$ in CAD5 cells by the Elispot cell infection assay with the titer in PrP-overexpressing tga20 transgenic mice by bioassay [7]. The same batch of recPrP $\mathrm{P}^{\mathrm{Sc}}$ was used for both assays (Fig. 1) and $\mathrm{ID}_{50} \mathrm{~s}$ were calculated following standard methods [14]. We found that the $\mathrm{ID}_{50}$ of $\operatorname{recPrP}^{\mathrm{Sc}}$ obtained from CAD5 cells was $3.33 \times 10^{5} / \mu \mathrm{g}$ recPrP and from tga 20 mice was $2.00 \times 10^{5} / \mu \mathrm{g}$ recPrP, indicating that the Elispot infection assay can be as sensitive as the bioassay. Although it is well known that prion infection in cultured cells can be influenced by the prion strain [13], the similar titers suggest that, at least for $\operatorname{recPrP} \mathrm{P}^{\mathrm{Sc}}$ generated with our procedure, the Elispot assay can be used to track changes of infectivity. Thus, we used this assay to analyze the relationship between prion infectivity and the PK-resistant recPrP $\mathrm{P}^{\mathrm{Sc}}$ conformation.

We first asked whether prion infectivity correlates with the increase of PK-resistant PrP during the sPMCA. Previous studies have shown that the end product of SPMCA is infectious [36-38], but we still don't know the details of how prion infectivity changes during the amplification process. Each round of sPMCA in our protocol consists of 48 cycles of sonication (30 s) and incubation (29 min and $30 \mathrm{~s}$ ). We collected samples at various time points during one round of PMCA (Fig. 2a), which showed that the proportion of PK-resistant recPrP increased gradually in the first $12 \mathrm{~h}$ and remained relatively unchanged in the second $12 \mathrm{~h}$. When the same set of samples was used to infect CAD5 cells, a time-dependent increase of prion infectivity was obvious and, notably, was mainly increased during the first $12 \mathrm{~h}$ (Fig. 2b). Comparing the infectivity at $10^{-3}$ dilution with the change in the PK resistance of recPrP produced a good correlation (Fig. $2 \mathrm{c}$ and d). These results suggest that the increase of prion infectivity correlated with the increase of PK-resistant recPrP during sPMCA, strongly supporting the idea that the conformational change of recPrP is responsible for the generation of prion infectivity during sPMCA.

\section{Prion infectivity is encoded within the PK-resistant recPrP ${ }^{\mathrm{Sc}}$ fragments}

RecPrP without any treatment is soluble (Fig. 3a, left), but almost all recPrP became insoluble after sPMCA, with a large portion of the insoluble recPrP remaining
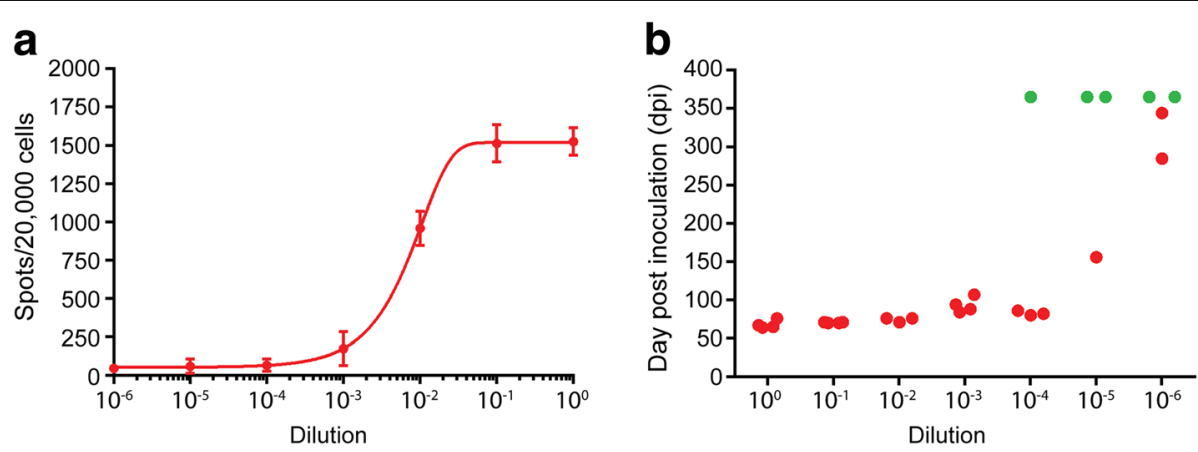

Fig. 1 Titer of recPrpSc infectivity determined by end-point titration with the Elispot cell infection assay (a) and the tga20 mouse bioassay (b). The same batch of recPrP ${ }^{S C}$ was subjected to 10 -fold serial dilution, and both undiluted and diluted recPrP ${ }^{S c}$ were used to infect naïve CAD5 cells or to intracerebrally inoculate tga20 mice. In $\mathbf{b}$, red dots indicate mice that reached the terminal stage of disease; green dots represent mice without any disease at the end of $365 \mathrm{dpi}$ 


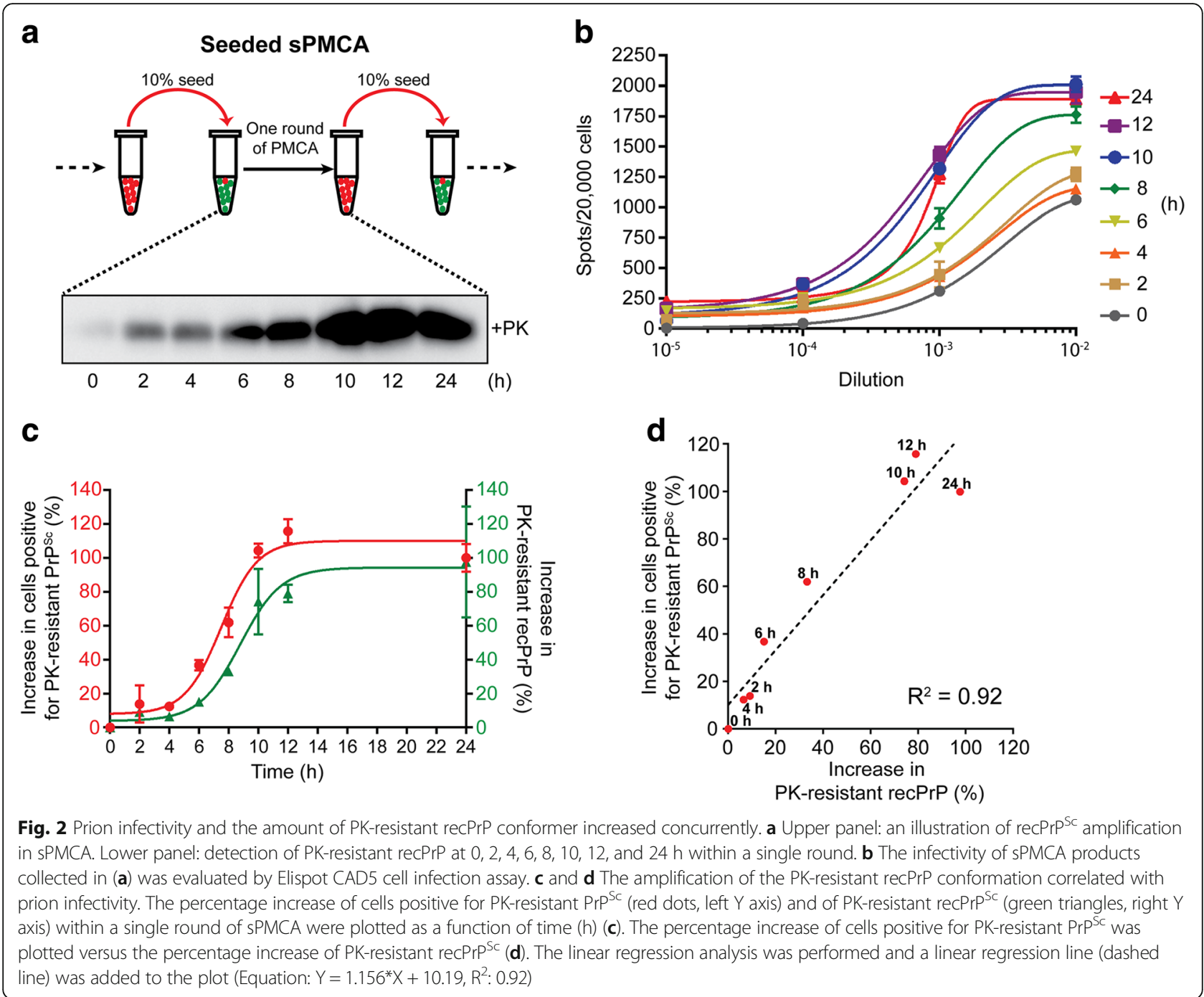

PK-sensitive (Fig. 3a, right). To determine whether prion infectivity is associated with the PK-resistant $\operatorname{rec} \operatorname{Pr} \mathrm{P}^{\mathrm{Sc}}$, we subject aliquots from the same batch of $\operatorname{recPrP}^{\mathrm{Sc}}$ preparation to Benzonase treatment (removing free RNA), PK digestion (removing PK-sensitive recPrP), or both, and compared their infectivity with that of the untreated aliquot. Benzonase digestion alone did not cause noticeable change in total recPrP (Fig. 3b). PK digestions with or without Benzonase generated similar amounts of $\mathrm{PK}$-resistant recPrP ${ }^{\mathrm{Sc}}$, in which $\mathrm{PK}$-sensitive recPrP and the $\mathrm{N}$-terminus of recPrP ${ }^{\mathrm{Sc}}$ were removed (Fig. 3b). When these treated aliquots were compared with untreated aliquot for infectivity in CAD5 cells, we found that none of the treatments appeared to alter infectivity (Fig. 3c). Because all the sPMCA products were in detergent solution and the pelleting step before cell infection would remove all free phospholipid POPG, this result suggests that the PK-resistant $\operatorname{recPrP}^{\mathrm{Sc}}$ aggregate contained all the prion infectivity. This conclusion was verified by bioassay in tga20 mice, which showed that the PK digestion and Benzonase treatment did not reduce the infectivity of the PMCA product. The results of mouse bioassays, which were performed with different batches of PMCA products, are summarized in Table 1.

$\mathrm{PrP}^{\mathrm{Sc}}$ can be almost completely digested by extended treatment with PK at high concentration [4]. We took advantage of this property and performed a harsh PK digestion to determine whether the disappearance of the PK-resistant recPrP ${ }^{\mathrm{Sc}}$ correlated with a reduction in prion infectivity. Relative to that of an untreated sample, our standard PK digestion $\left(50 \mu \mathrm{g} / \mathrm{mL}, 37^{\circ} \mathrm{C}, 30 \mathrm{~min}\right)$ did not cause any change in the infectivity (Fig. 4a). An extended digestion $\left(50 \mu \mathrm{g} / \mathrm{mL}, 37{ }^{\circ} \mathrm{C}, 16 \mathrm{~h}\right)$ not only resulted in much less PK-resistant recPrP ${ }^{\mathrm{Sc}}$ (Fig. 4a) but also dramatically decreased the infectivity (Fig. 4b). When recPrP ${ }^{\mathrm{Sc}}$ was subjected to an extreme PK digestion $(1 \mathrm{mg} /$ $\mathrm{mL}, 37^{\circ} \mathrm{C}, 16 \mathrm{~h}$ ), the PK-resistant recPrP band was barely detectable, and concomitantly the prion infectivity was 
a
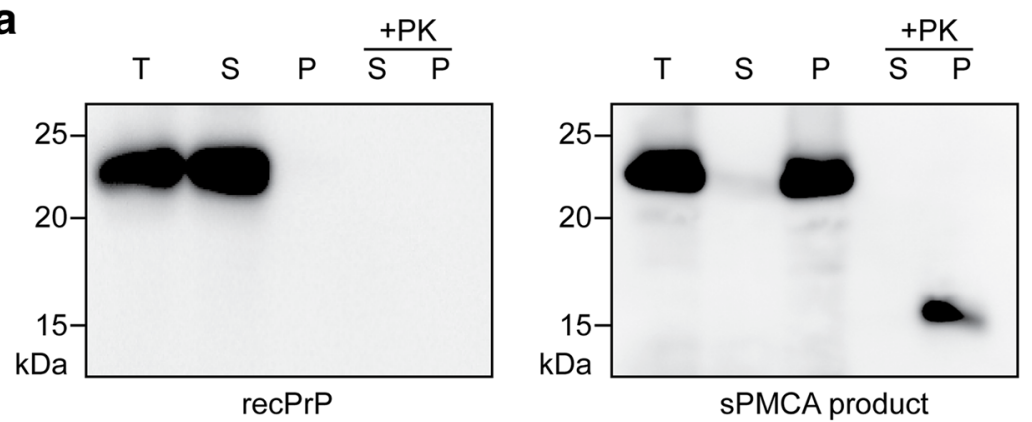

b

C
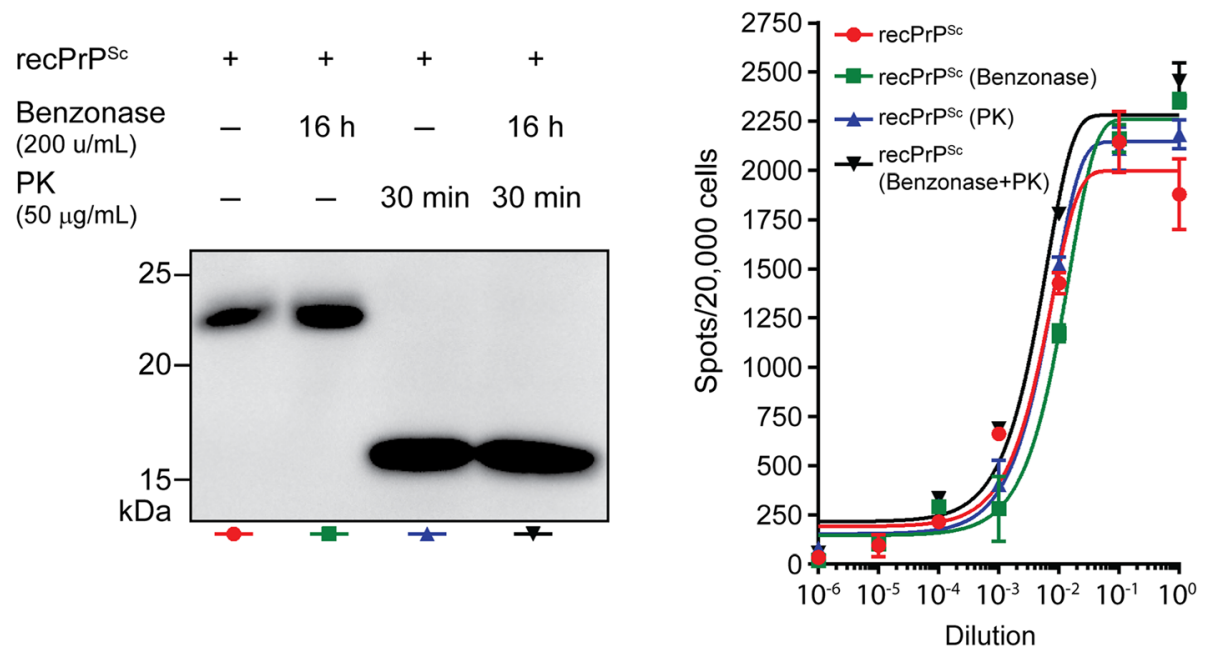

Fig. 3 PK digestion did not reduce prion infectivity. a RecPrP (left panel) and the sPMCA product (right panel) were subjected to ultracentrifugation $\left(100,000 \times g, 1 \mathrm{~h}, 4^{\circ} \mathrm{C}\right)$ with or without prior PK digestion $\left(50 \mu \mathrm{g} / \mathrm{mL}, 30 \mathrm{~min}, 37^{\circ} \mathrm{C}\right)$ as indicated $(\mathrm{T}$ : total input, $1 \mu \mathrm{L}$; S: supernatant fraction, $1 \mu \mathrm{L}$; P: pellet fraction, $1 \mu \mathrm{L}$ ). For PK digestion, $10 \mu \mathrm{L}$ of sample from the supernatant or pellet fraction was used. $\mathbf{b}$ The same batch of recPrPS ${ }^{\mathrm{Sc}}$ was untreated or was treated with Benzonase, PK, or both, as indicated. c Prion infectivity of samples in (b) was evaluated by Elispot cell infection assay

virtually eliminated (Fig. 4b). These results provided further evidence supporting the correlation of prion infectivity to the conformation of PK-resistant recPrP $\mathrm{P}^{\mathrm{Sc}}$.

\section{Discussion}

In this study, we dissected the propagation of recombinant prion and established a clear correlation between the amplification of the PK-resistant recPrP ${ }^{\mathrm{Sc}}$ conformation and the increase of prion infectivity. Moreover, our findings demonstrated that the recombinant prion infectivity is encoded within the structure of its PK-resistant fragments, confirming that the self-propagating, $\mathrm{PK}$-resistant $\operatorname{recPrP}^{\mathrm{Sc}}$ is the infectious entity.

Table 1 Bioassay in tga20 mice via intracerebral inoculation ${ }^{a}$

\begin{tabular}{|c|c|c|c|c|}
\hline Experiment & Inoculum & & Attack rate $\left(N_{\text {diseased }} / N_{\text {total }}\right)$ & Survival time for individual mice (dpi) \\
\hline$\# 1$ & recPrpsc & \multirow{3}{*}{$\begin{array}{l}\text { Cofactors for \#1-\#3: } \\
\text { - POPG } \\
\text { - Total mouse liver RNA }\end{array}$} & $100 \%(4 / 4)$ & $85,86,98,121$ \\
\hline \#2 & recPrpsc & & $100 \%(3 / 3)$ & $91,93,94$ \\
\hline \#3 & recPrPsc (after Benzonase+PK digestion) & & $100 \%(5 / 5)$ & $73,76,76,80,80$ \\
\hline \#4 & recPrPsc & \multirow{3}{*}{$\begin{array}{l}\text { Cofactors for \#4-\#6: } \\
\text { - POPG } \\
\text { - Synthetic Poly rA RNA }\end{array}$} & $100 \%(4 / 4)$ & $104,109,115,119$ \\
\hline$\# 5^{\mathrm{b}}$ & recPrpsc & & $100 \%(4 / 4)$ & $95,95,104,110$ \\
\hline$\# 6^{\mathrm{b}}$ & recPrPSc (after Benzonase+PK digestion) & & $100 \%(4 / 4)$ & $95,106,108,109$ \\
\hline
\end{tabular}

${ }^{\mathrm{a} D i f f e r e n t}$ batches of recPrP ${ }^{\mathrm{Sc}}$ were used

${ }^{\mathrm{b}}$ The same batch of recPrP ${ }^{\mathrm{SC}}$ was used to for these two experiments

'See reference [37]

${ }^{d}$ dpi: days post injection 


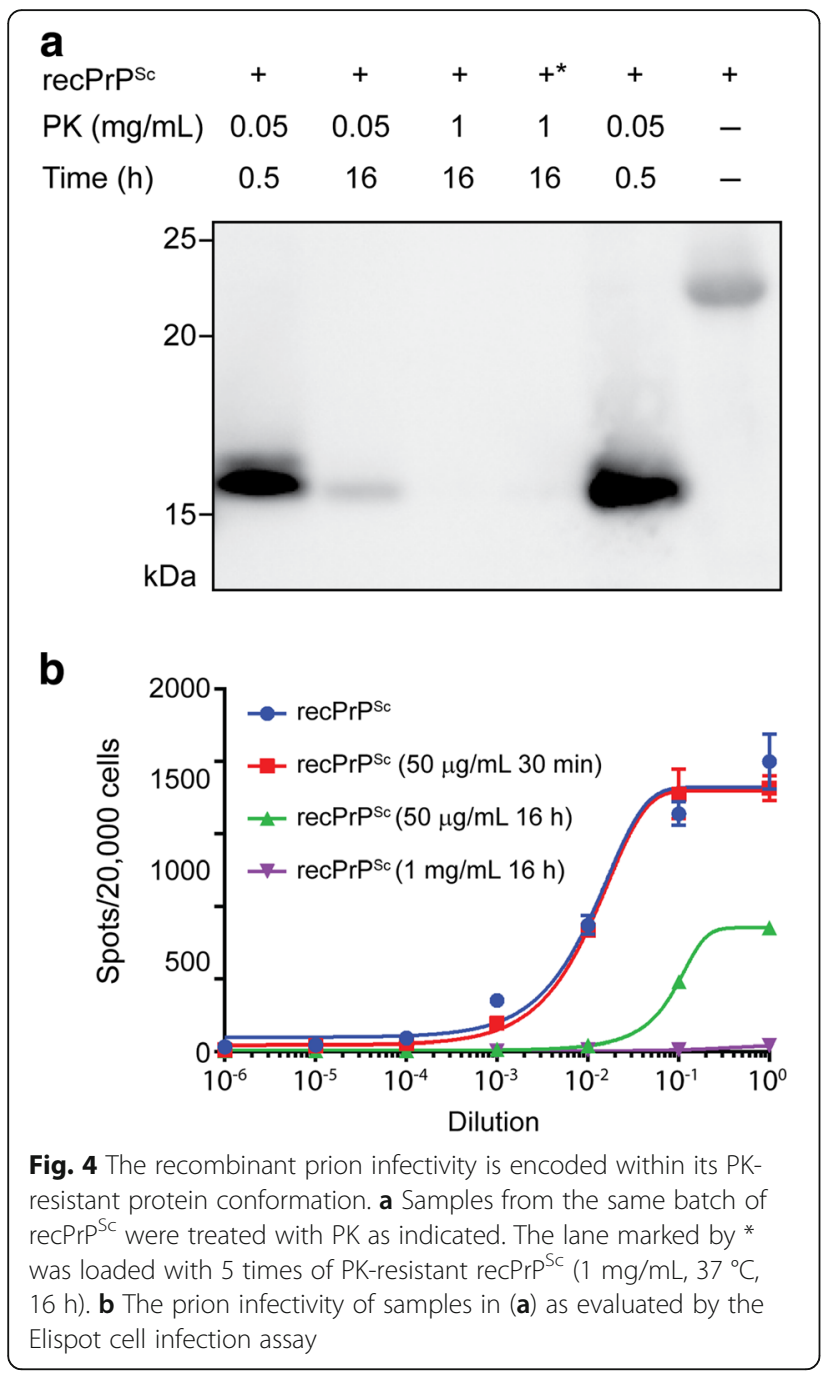

Prion infectivity is classically determined by an endpoint dilution assay in animals [9], which is accurate but time consuming (>1 year) and costly. That is why it is not used for detailed studies of prion infectivity. Weissmann and colleagues developed the new Elispot cellbased prion infection assay $[10,11,13,14]$. Relative to the traditional animal bioassay, it is rapid, cost-effective, and more suitable for detailed characterization of prion infectivity. The Elispot assay has the drawback that only a few cell lines are susceptible to prion infection, and those cell lines have shown different sensitivities to various prion strains [13]. Among the susceptible cell lines, CAD5 cells have a high susceptibility to prion infection and a high sensitivity to almost all murine prion strains tested $[11,13]$. Thus, we selected CAD5 cells to test our in vitro-generated recPrP $\mathrm{P}^{\mathrm{Sc}}$. The similar levels of infectivity found by the CAD5 cell infection assay and the classic tga20 mouse bioassay support that idea the cell assay is well suited for measuring the infectivity of the recPrP $\mathrm{Pc}^{\mathrm{Sc}}$ generated by our protocol.
The CAD5 cells and the Elispot assay allowed us to perform a detailed characterization of the relationship between $\mathrm{PK}$ resistance and prion infectivity. Although $\mathrm{PrP}^{\mathrm{Sc}}$ has been traditionally defined as the PK-resistant PrP species, the so-called PK resistance reflects its higher tolerance to $\mathrm{PK}$ digestion relative to normal $\operatorname{PrP}^{\mathrm{C}}$. However, the generally accepted PK digestion conditions are chosen for practicality, which ensure the removal of all normal $\operatorname{PrP}^{\mathrm{C}}$ every time but may degrade some $\operatorname{PrP}^{\mathrm{Sc}}$ species as well. Using the standard PK digestion conditions, several groups have found PK-sensitive $\operatorname{PrP}^{\mathrm{Sc}}$ with various methods $[5,15$, 17, 24-26, 28, 32]. Cronier et al. reported that a large proportion of the Rocky Mountain Laboratory (RML) murine prion strain consists of at least 2 types of PKsensitive $\operatorname{PrP}^{\mathrm{Sc}}$ : one is thermolysin-resistant and contributes little to prion infectivity, while the other is thermolysinsensitive and makes up of about $80 \%$ of the RML infectious titer as measured by the cell-based assay [5]. A more recent study by Sajnani et al. showed that the PK-sensitive $\operatorname{PrP}^{\mathrm{Sc}}$ isolated from diseased brains by ultracentrifugation is also infectious, and its infectivity (measured by animal bioassay) is comparable to that of the PK-resistant $\operatorname{PrP}^{\mathrm{Sc}}$ [26]. More importantly, they demonstrated that the PK-sensitive and PK-resistant $\mathrm{PrP}^{\mathrm{Sc}}$ share common structural features [26], indicating that the basic units of these two types of $\operatorname{PrP}^{\mathrm{Sc}}$ aggregate share the same protein conformation. Thus, the difference in PK sensitivity could be a result of the degree of multimerization, binding to other molecules, or both.

An interesting finding of our study is that the prion infectivity was encoded almost exclusively by the PKresistant recPrP conformation, which suggests that compared to $\mathrm{PrP}^{\mathrm{Sc}}$ from diseased tissues that consists of both PK-resistant and -sensitive PrP forms, the recPrP $\mathrm{Pc}^{\mathrm{Sc}}$ is relatively more homogeneous with recPrP species of higher PK-resistance. The simplest explanation would be that the in vitro-generated $\operatorname{recPrP}^{\mathrm{Sc}}$ might be structurally different from $\operatorname{PrP}^{\mathrm{Sc}}$ from diseased tissue, which could be a result of the lack of post-translational modification or of a difference in $\operatorname{PrP}^{\mathrm{Sc}}$ structure. This is unlikely, however, because the biological activity and the structural characteristics of recPrP $\mathrm{P}^{\mathrm{Sc}}$ are almost identical to those of $\operatorname{PrP}^{\mathrm{Sc}}[35,38]$, and a recent limitedproteolysis study revealed a shared structure between recPrP $\mathrm{P}^{\mathrm{Sc}}$ and brain-derived $\operatorname{PrP}^{\mathrm{Sc}}$ [29]. A more plausible explanation could be the simplicity of the in vitro recPrP conversion system. Besides recPrP, only Triton X-100 and two cofactors, POPG and RNA, are present, which is different from the multitude of molecules present in tissue lysates. As a result, the converted $\mathrm{recPrP} \mathrm{P}^{\mathrm{Sc}}$ is less likely to bind to other molecules to maintain the oligomeric or the less PK-resistant state. Instead, in the absence of other molecules, $\operatorname{recPrP}^{\mathrm{Sc}}$ is probably more prone to multimerization to form aggregates with higher PK-resistance. Consistent with this idea, Noble et al. 
reported that in their recPrP ${ }^{\mathrm{Sc}}$ preparation system that uses only one cofactor, around $90 \%$ of recPrP was converted into the PK-resistant form [16]. Although it remains unclear how much of infectivity the 10\% PKsensitive recPrP may account for, the higher conversion rate in their system supports the notion that less cofactor may result in more aggregated and PK-resistant recPrP. It is also worth noting that our recPrP ${ }^{\mathrm{Sc}}$ and the recPrP ${ }^{\mathrm{Sc}}$ generated by Noble et al. appear to be two different prion strains [6]. It will be of high interest to compare their structural differences in the future.

The fact that infectivity is exclusively found in the PKresistant $\mathrm{recPrP}^{\mathrm{Sc}}$ species offers a great advantage in using this material to study the molecular basis of prion infectivity, which is one of the most important applications of the in vitro conversion system. The aggregated nature of $\mathrm{PrP}^{\mathrm{Sc}}$ in diseased tissues limits the possibility of applying conventional structural biology tools [39]. It requires the integration of multiple biochemical and biophysical techniques to piece together the high-resolution $\operatorname{PrP}^{\mathrm{Sc}}$ structure, which demands a reliable source of prions [29,39]. As mentioned above, the recPrP ${ }^{\mathrm{Sc}}$ generated in our system recapitulates all the properties of native prions and is a convenient and robust source of $\operatorname{PrP}^{\mathrm{Sc}}[1,29,36-38]$. Because infectivity is associated with PK-resistant recPrP $\mathrm{P}^{\mathrm{Sc}}$, we will be able to remove all PK-sensitive (non-infectious) recPrP species by a simple proteinase $\mathrm{K}$ digestion. The increased homogeneity will greatly facilitate structural studies of $\mathrm{recPrP}^{\mathrm{Sc}}$ and studies to identify potential therapeutic agents that are able to neutralize prion infectivity.

\section{Conclusions}

In conclusion, our results clearly establish that the structure of the PK-resistant recPrP ${ }^{\mathrm{Sc}}$ fragments contains all the information for prion infectivity and there is no infectious $\mathrm{PK}$-sensitive $\mathrm{recPrP} \mathrm{P}^{\mathrm{Sc}}$ in the synthetically generated prion prepared with our protocol. Moreover, we also show that the increase of the PK-resistant recPrP conformation during PMCA correlates with an increase of prion infectivity, supporting that recPrP $\mathrm{P}^{\mathrm{Sc}}$ is indeed a protein conformation based infectious agent.

\section{Acknowledgements}

We would like to thank Dr. Charles Weissmann at Scripps Florida for the CAD5 cell line and David Nadziejka at Van Andel Research Institute for editing the manuscript.

\section{Funding}

This work was supported by NIH grants R01NS060729 and R01NS071035.

\section{Authors' contributions}

JM designed the study, analyzed data, and wrote the main manuscript text, FW designed the study, performed the experiments, generated and analyzed data, and wrote the main manuscript text, XW performed the experiments, generated and analyzed data, RA performed the experiments. All authors reviewed and approved the final manuscript.
Consent for publication

Not applicable.

\section{Competing interests}

The authors declare that they have no competing interests.

\section{Publisher's Note}

Springer Nature remains neutral with regard to jurisdictional claims in published maps and institutional affiliations.

\section{Author details}

${ }^{1}$ Center for Neurodegenerative Science, Van Andel Research Institute, 333 Bostwick Avenue N.E., Grand Rapids, MI 49503, USA. ${ }^{2}$ National Institute of Oceanography and Fisheries (NIOF), Cairo 11516, Egypt.

Received: 12 March 2018 Accepted: 11 April 2018

Published online: 24 April 2018

\section{References}

1. Abskharon R, Wang F, Vander Stel KJ, Sinniah K, Ma J (2016) The role of the unusual threonine string in the conversion of prion protein. Sci Rep 6:38877

2. Aguzzi A, Baumann F, Bremer J (2008) The prion's elusive reason for being. Annu Rev Neurosci 31:439-477

3. Aguzzi A, Lakkaraju AKK, Frontzek K (2018) Toward therapy of human prion diseases. Annu Rev Pharmacol Toxicol 58:331-351

4. Appel TR, Dumpitak C, Matthiesen U, Riesner D (1999) Prion rods contain an inert polysaccharide scaffold. Biol Chem 380(11):1295-1306

5. Cronier S, Gros N, Tattum MH, Jackson GS, Clarke AR, Collinge J, Wadsworth JD (2008) Detection and characterization of proteinase K-sensitive diseaserelated prion protein with thermolysin. Biochem J 416(2):297-305

6. Deleault NR, Walsh DJ, Piro JR, Wang F, Wang X, Ma J, Rees JR, Supattapone S (2012) Cofactor molecules maintain infectious conformation and restrict strain properties in purified prions. Proc Natl Acad Sci U S A 109(28):E1938-E1946

7. Fischer M, Rulicke T, Raeber A, Sailer A, Moser M, Oesch B, Brandner S, Aguzzi A, Weissmann C (1996) Prion protein (PrP) with amino-proximal deletions restoring susceptibility of PrP knockout mice to scrapie. EMBO J 15(6):1255-1264

8. Jucker M, Walker LC (2013) Self-propagation of pathogenic protein aggregates in neurodegenerative diseases. Nature 501(7465):45-51

9. Kimberlin RH, Walker CA (1978) Pathogenesis of mouse scrapie: effect of route of inoculation on infectivity titres and dose-response curves. J Comp Pathol 88(1):39-47

10. Klohn PC, Stoltze L, Flechsig E, Enari M, Weissmann C (2003) A quantitative, highly sensitive cell-based infectivity assay for mouse scrapie prions. Proc Natl Acad Sci U S A 100(20):11666-11671

11. Li J, Browning S, Mahal SP, Oelschlegel AM, Weissmann C (2010) Darwinian evolution of prions in cell culture. Science 327(5967):869-872

12. Ma J, Wang F (2014) Prion disease and the 'protein-only hypothesis'. Essays Biochem 56:181-191

13. Mahal SP, Baker CA, Demczyk CA, Smith EW, Julius C, Weissmann C (2007) Prion strain discrimination in cell culture: the cell panel assay. Proc Natl Acad Sci U S A 104(52):20908-20913

14. Mahal SP, Demczyk CA, Smith EW Jr, Klohn PC, Weissmann C (2008) Assaying prions in cell culture: the standard scrapie cell assay (SSCA) and the scrapie cell assay in end point format (SCEPA). Methods Mol Biol 459:49-68

15. Nazor KE, Kuhn F, Seward T, Green M, Zwald D, Purro M, Schmid J, Biffiger K, Power AM, Oesch B et al (2005) Immunodetection of disease-associated mutant PrP, which accelerates disease in GSS transgenic mice. EMBO J 24(13):2472-2480

16. Noble GP, Wang DW, Walsh DJ, Barone JR, Miller MB, Nishina KA, Li S, Supattapone S (2015) A structural and functional comparison between infectious and non-infectious autocatalytic recombinant PrP conformers. PLoS Pathog 11(6):e1005017

17. Pastrana MA, Sajnani G, Onisko B, Castilla J, Morales R, Soto C, Requena JR (2006) Isolation and characterization of a proteinase K-sensitive PrPSC fraction. Biochemistry 45(51):15710-15717

18. Polymenidou M, Moos R, Scott M, Sigurdson C, Shi YZ, Yajima B, HafnerBratkovic I, Jerala R, Hornemann S, Wuthrich K et al (2008) The POM monoclonals: a comprehensive set of antibodies to non-overlapping prion protein epitopes. PLoS One 3(12):e3872

19. Prusiner SB (1982) Novel proteinaceous infectious particles cause scrapie. Science 216(4542):136-144 
20. Prusiner SB (1998) Prions. Proc Natl Acad Sci U S A 95(23):13363-13383

21. Prusiner SB (2012) Cell biology. A unifying role for prions in neurodegenerative diseases. Science 336(6088):1511-1513

22. Riek R, Hornemann S, Wider G, Billeter M, Glockshuber R, Wuthrich K (1996) NMR structure of the mouse prion protein domain PrP(121-321). Nature 382(6587):180-182

23. Riek R, Hornemann S, Wider G, Glockshuber R, Wuthrich K (1997) NMR characterization of the full-length recombinant murine prion protein, mPrP(23-231). FEBS Lett 413(2):282-288

24. Safar J, Wille H, Itri V, Groth D, Serban H, Torchia M, Cohen FE, Prusiner SB (1998) Eight prion strains have $\operatorname{PrP}(\mathrm{SC})$ molecules with different conformations. Nat Med 4(10):1157-1165

25. Safar JG, Geschwind MD, Deering C, Didorenko S, Sattavat M, Sanchez H, Serban A, Vey M, Baron H, Giles K et al (2005) Diagnosis of human prion disease. Proc Natl Acad Sci U S A 102(9):3501-3506

26. Sajnani G, Silva CJ, Ramos A, Pastrana MA, Onisko BC, Erickson ML, Antaki EM, Dynin I, Vazquez-Fernandez E, Sigurdson CJ et al (2012) PK-sensitive PrP is infectious and shares basic structural features with PK-resistant PrP. PLoS Pathog 8(3):e1002547

27. Sandberg MK, Al-Doujaily H, Sharps B, Clarke AR, Collinge J (2011) Prion propagation and toxicity in vivo occur in two distinct mechanistic phases. Nature 470(7335):540-542

28. Saverioni D, Notari S, Capellari S, Poggiolini I, Giese A, Kretzschmar HA, Parchi P (2013) Analyses of protease resistance and aggregation state of abnormal prion protein across the spectrum of human prions. J Biol Chem 288(39):27972-27985

29. Sevillano AM, Fernandez-Borges N, Younas N, Wang F, Elezgarai SR, Bravo S, Vazquez-Fernandez E, Rosa I, Erana H, Gil D et al (2018) Recombinant PrPSc shares structural features with brain-derived PrPSc: insights from limited proteolysis. PLoS Pathog 14(1):e1006797.

30. Smirnovas V, Baron GS, Offerdahl DK, Raymond GJ, Caughey B, Surewicz WK (2011) Structural organization of brain-derived mammalian prions examined by hydrogen-deuterium exchange. Nat Struct Mol Biol 18(4):504-506

31. Soto C (2012) Transmissible proteins: expanding the prion heresy. Cell 149(5):968-977

32. Thackray AM, Hopkins L, Bujdoso R (2007) Proteinase K-sensitive diseaseassociated ovine prion protein revealed by conformation-dependent immunoassay. The Biochemical journal 401(2):475-483

33. Vazquez-Fernandez E, Vos MR, Afanasyev P, Cebey L, Sevillano AM, Vidal E, Rosa I, Renault L, Ramos A, Peters PJ et al (2016) The structural architecture of an infectious mammalian prion using Electron Cryomicroscopy. PLoS Pathog 12(9):e1005835

34. Wang F, Wang $X$, Ma J (2011) Conversion of bacterially expressed recombinant prion protein. Methods 53(3):208-213

35. Wang F, Wang X, Orru CD, Groveman BR, Surewicz K, Abskharon R, Imamura M, Yokoyama T, Kim YS, Vander Stel KJ et al (2017) Self-propagating, protease-resistant, recombinant prion protein conformers with or without in vivo pathogenicity. PLoS Pathog 13(7):e1006491

36. Wang F, Wang X, Yuan CG, Ma J (2010) Generating a prion with bacterially expressed recombinant prion protein. Science 327(5969):1132-1135

37. Wang F, Zhang Z, Wang X, Li J, Zha L, Yuan CG, Weissmann C, Ma J (2012) Genetic informational RNA is not required for recombinant prion infectivity. J Virol 86(3):1874-1876

38. Wang X, McGovern G, Zhang Y, Wang F, Zha L, Jeffrey M, Ma J (2015) Intraperitoneal infection of wild-type mice with synthetically generated mammalian prion. PLoS Pathog 11(7):e1004958

39. Wille H, Requena JR. The Structure of PrPSC Prions. Pathogens. 2018;7(1):20 https://doi.org/10.3390/pathogens7010020.

40. Zhang Z, Zhang Y, Wang F, Wang X, Xu Y, Yang H, Yu G, Yuan C, Ma J (2013) De novo generation of infectious prions with bacterially expressed recombinant prion protein. FASEB journal : official publication of the Federation of American Societies for Experimental Biology 27(12):4768-4775

41. Zweckstetter $M$, Requena JR, Wille $H$ (2017) Elucidating the structure of an infectious protein. PLoS Pathog 13(4):e1006229

\section{Ready to submit your research? Choose BMC and benefit from:}

- fast, convenient online submission

- thorough peer review by experienced researchers in your field

- rapid publication on acceptance

- support for research data, including large and complex data types

- gold Open Access which fosters wider collaboration and increased citations

- maximum visibility for your research: over $100 \mathrm{M}$ website views per year

At BMC, research is always in progress.

Learn more biomedcentral.com/submissions 